\title{
Long-term resource addition to a detrital food web yields a pattern of responses more complex than pervasive bottom-up control
}

\author{
Kendra L. Lawrence ${ }^{1}{ }^{\text {, }}$ David H Wise ${ }^{\text {Corresp. } 2}$ \\ 1 KL2 Consulting, LLC, Silver Spring, Maryland, United States \\ 2 Department of Biological Sciences, and Institute for Environmental Science and Policy, University of Illinois at Chicago, Chicago, Illinois, United States \\ Corresponding Author: David H Wise \\ Email address: dhwise@uic.edu
}

Background. Theory predicts strong bottom-up control in detritus-based food webs, yet field experiments with detritus-based terrestrial systems have uncovered contradictory evidence regarding the strength and pervasiveness of bottom-up control processes. Two factors likely leading to contradictory results are experiment duration, which influences exposure to temporal variation in abiotic factors such as rainfall and affects the likelihood of detecting approach to a new equilibrium; and openness of the experimental units to immigration and migration. To investigate the contribution of these two factors, we conducted a long-term experiment with open and fenced plots in the forest that was the site of an earlier, short-term experiment (3.5 months) with open plots (Chen \& Wise 1999) that produced evidence of strong bottom-up control for 14 taxonomic groupings of primary consumers of fungi and detritus (microbi-detritivores) and their predators. Methods. We added artificial high-quality detritus to ten $2 \times 2$-m forest-floor plots at bi-weekly intervals from April through September in three consecutive years (Supplemented treatment). Ten comparable Ambient plots were controls. Half of the Supplemented and Ambient plots were enclosed by metal fencing. Results. Arthropod community structure (based upon 18 response variables) diverged over time between Supplemented and Ambient treatments, with no effect of Fencing on the multivariate response pattern. Fencing possibly influenced only ca. $30 \%$ of the subsequent univariate analyses. Multi- and univariate analyses revealed bottom-up control during Year 1 of some, but not all, microbi-detritivores and predators. During the following two years the pattern of responses became more complex than that observed by Chen \& Wise (1999). Some taxa showed consistent bottom-up control whereas others did not. Variation across years could not be explained completely by differences in rainfall because some taxa exhibited negative, not positive, responses to detrital supplementation. Discussion. Our 3-yr experiment did not confirm the conclusion of strong, pervasive bottom-up control of both microbi-detritivores and predators reported 
by Chen and Wise (1999). Our longer-term experiment revealed a more complex pattern of responses, a pattern much closer to the range of outcomes reported in the literature for many short-term experiments. Much of the variation in responses across studies likely reflects variation in abiotic and biotic factors and the quality of added detritus. Nevertheless, it is also possible that long-term resource enhancement can drive a community towards a new equilibrium state that differs from what would have been predicted from the initial short-term responses exhibited by primary and secondary consumers. 
1 Long-term resource addition to a detrital food web yields a pattern

2 of responses more complex than pervasive bottom-up control

3

4

5 Kendra L. Lawrence ${ }^{1}$, David H. Wise ${ }^{2}$

6

$7 \quad{ }^{1}$ KL2 Consulting, LLC, Silver Spring, MD 20910, USA

$8{ }^{2}$ Deptartment of Biological Sciences, and Institute for Environmental Science and Policy,

9 University of Illinois at Chicago, Chicago, IL 60607, USA.

10

11

12 Corresponding Author:

13 David H. Wise ${ }^{2}$

14

15 Email address: dhwise@uic.edu

16

17

18 
19 Abstract

20

Background. Theory predicts strong bottom-up control in detritus-based food webs, yet field experiments with detritus-based terrestrial systems have uncovered contradictory evidence regarding the strength and pervasiveness of bottom-up control processes. Two factors likely leading to contradictory results are experiment duration, which influences exposure to temporal variation in abiotic factors such as rainfall and affects the likelihood of detecting approach to a new equilibrium; and openness of the experimental units to immigration and migration. To investigate the contribution of these two factors, we conducted a long-term experiment with open and fenced plots in the forest that was the site of an earlier, short-term experiment (3.5 months) with open plots (Chen \& Wise 1999) that produced evidence of strong bottom-up control for 14 taxonomic groupings of primary consumers of fungi and detritus (microbi-detritivores) and their predators.

Methods. We added artificial high-quality detritus to ten 2 × 2-m forest-floor plots at biweekly intervals from April through September in three consecutive years (Supplemented treatment). Ten comparable Ambient plots were controls. Half of the Supplemented and Ambient plots were enclosed by metal fencing.

Results. Arthropod community structure (based upon 18 response variables) diverged over time between Supplemented and Ambient treatments, with no effect of Fencing on the multivariate response pattern. Fencing possibly influenced only ca. $30 \%$ of the subsequent univariate analyses. Multi- and univariate analyses revealed bottom-up control during Year 1 of some, but not all, microbi-detritivores and predators. During the following two years the pattern of responses became more complex than that observed by Chen \& Wise (1999). Some taxa showed consistent bottom-up control whereas others did not. Variation across years could not be explained completely by 
42 differences in rainfall because some taxa exhibited negative, not positive, responses to detrital

43 supplementation.

44 Discussion. Our 3-yr experiment did not confirm the conclusion of strong, pervasive bottom45 up control of both microbi-detritivores and predators reported by Chen and Wise (1999). Our longer46 term experiment revealed a more complex pattern of responses, a pattern much closer to the range of 47 outcomes reported in the literature for many short-term experiments. Much of the variation in 48 responses across studies likely reflects variation in abiotic and biotic factors and the quality of added 49 detritus. Nevertheless, it is also possible that long-term resource enhancement can drive a community 50 towards a new equilibrium state that differs from what would have been predicted from the initial 51 short-term responses exhibited by primary and secondary consumers.

52 


\section{Introduction}

55

56 Classical theory predicts extensive bottom-up control in detritus-based food webs. However,

57 accumulating empirical findings and modeling research suggest that bottom-up control may not

58 be as strong and pervasive as hypothesized, and that a mixture of bottom-up and top-down

59 control processes characterizes soil food webs (e.g. Bardgett \& Wardle 2010; McCann 2012;

60

Moore \& deRuiter 2012; Pimm 2002; Wardle 2002). Debates over the strength of bottom-up and

top-down control in food webs with many generalist predators (a characteristic of soil

communities) intensified in parallel with increasing reliance on controlled field experiments to

test theory (e.g. Hairston 1989; Hairston \& Hairston 1993; McCann 2012; Menge 2000; Moore

et al. 2004; Moore \& deRuiter 2012; Polis \& Strong 1996; Polis 1996; Resetarits 1998).

Making inferences about population control processes from field experiments is not straightforward (Raffaelli \& Moller 2000). Two major challenges are space and time. Species interactions occur over a spectrum of spatial scales. Finding an appropriate size for experimental units is difficult, especially given opposing constraints imposed by the desire for realism, the requirement of sufficient replication for adequate statistical power, and the frequent need to impose barriers to migration by using cages or fencing (Gardner et al. 2004; Hurlbert 1984; Raffaelli \& Moller 2000; Resetarits 1998). Perhaps an even greater challenge is time. Short-term experiments often fail to capture the spectrum of responses caused by temporal variation in abiotic factors such as rainfall. Furthermore, short-term experiments are unlikely to reveal new equilibria because detecting the consequences of time lags within chains of indirect effects requires many generations of interacting organisms (Bender et al. 1984; Osenberg \& Mittelbach 1996; Yodzis 1988). 
The most direct way to uncover the strength of bottom-up control and its pervasiveness

78 across trophic levels is to observe how adding energy- and/or nutrient-rich detritus to replicated plots in a field experiment alters densities of major taxa of primary and secondary consumers. Such experiments in terrestrial ecosystems have been conducted in prairies and grasslands (Fountain et al. 2008; Hoekman et al. 2011; Oelbermann et al. 2008; Patrick et al. 2012) and forests (Chen \& Wise 1999; David et al. 1991; Lessard et al. 2011; Maraun et al. 2001; Raub et al. 2014; Salamon et al. 2006; Scheu \& Schaefer 1998; Yang 2006). Most experiments uncovered some evidence for bottom-up control, but the strength and pervasiveness across trophic levels of the responses varied substantially. In some studies, supplementing detrital input resulted in increased populations of primary consumers and their predators. In other experiments the predators showed no response. Sometimes effects occurred across many taxa, sometimes they were limited to a few, and in a few instances effects of detrital supplementation were negative. Such variability in outcomes likely reflects differences between experiments in many factors, both environmental and logistical: levels of limiting abiotic factors (i.e. rainfall and temperature) during the experiment; type, quality, and amount of added detritus; taxonomic resolution of the response variables; plot size; number of replicates; whether the plots were open or fenced; and duration of the experiment.

Long-term experiments are more likely to capture the influence of variation in abiotic factors and also are more likely to reveal indirect effects that propagate at different rates through a complex food web. Among experiments conducted to date, densities of some trophic groups occasionally responded negatively to addition of detritus. Do these negative effects reflect differential responses by predators to resource-addition combined with intensification of top-down control processes along a subset of trophic pathways due to the indirect effects of trophic-level omnivory in a detritus-based food web (Polis \& Strong 1996, Halaj \& Wise 2002, Oelbermann et al. 2008)? 
101 Were different pathways of top-down control processes modulating the strength of bottom-up

102 control, producing different responses among trophic levels as the system moved towards a new

103 equilibrium state? Direct manipulation of predator densities in similar detritus-based food webs

104 has revealed top-down control, including trophic cascades affecting decomposition rates (Kajak

105 1997; Kajak \& Jakubczyk 1977; Lawrence \& Wise 2004; Lensing \& Wise 2006; Wardle 2002;

106 Wise 2004). However, negative effects of detrital enhancement on densities of primary

107 consumers and predators were only infrequently observed in previous experiments. A caveat is

108 needed, though, as most resource-enhancement experiments have been relatively brief compared

109 to the generation times of species in the community [one exception is the 4-yr manipulation of

110 nutrients in a grassland (Patrick et al. 2012)]. Furthermore, no experiments of both short-and

111 long-term duration have been conducted with the same system, so the question remains

112 unanswered of whether short-term resource enhancement produces patterns predictive of longer-

113 term resource-enhancement experiments.

114 Detrital-enhancement experiments have been conducted with both fenced and open plots.

115 Fencing, which has the potential to reduce confounding effects of emigration and immigration on

116 responses of the target taxa to resource enhancement, is potentially most critical for smaller

117 experimental units. This is especially true if the experiment is conducted over many generations

118 of the affected organisms. Positive responses in open plots possibly underestimate the actual

119 strength of bottom-up control because populations that increased in response to detrital

120 supplementation can decline as emigrants leave for areas outside the plots where densities are

121 lower. Similarly, unexpected decreases in density in supplemented unfenced plots might be

122 masked by augmentation of densities due to immigration from outside. Thus, we hypothesized

123 that fencing the plots would produce more realistic estimates of the strength of bottom-up 
124 control, or conversely, would more likely reveal population declines resulting from cascading 125 indirect effects.

Here we report results of a 3-year detrital-addition experiment in a secondary oak-maple-

127 hickory forest, with a few scattered pine trees, in Madison Co., Kentucky, USA. Our experiment

128 was conducted within $\sim 0.5 \mathrm{~km}$ of the sites of a previous similar, but short-term (3.5-months),

129 experiment that utilized open (unfenced) forest-floor plots (Chen \& Wise 1999) — referred to as

130 "CW99" from now on. The earlier experiment in this forest produced clear evidence of detrital

131 resource limitation [sensu Osenberg \& Mittelbach (1996)] i.e. relatively rapid elevation of

132 population densities of both primary and secondary consumers in response to addition of high-

133 quality detritus. Major groups of primary consumers, the microbi-detritivores (grazers of fungi

134 and consumers of organic debris), were at least 2-3x more abundant in supplemented than

135 control plots. Major arthropod predators were $\sim 2 \mathrm{x}$ as abundant. No taxa were less abundant in

136 the resource-supplemented treatment. Because the plots were not fenced, emigration of some

137 taxa that responded positively to resource supplementation might have weakened the observed

138 magnitude of bottom-up control. Similarly, immigration of taxa that had actually declined in

139 density might have erased the negative treatment response. Our experiment expanded the design

140 of CW99 to answer two questions (the first, logistical; the second, conceptual): (1) How would a

141 barrier that reduced migration/immigration of some groups of ground arthropods affect

142 conclusions about bottom-up control? (2) Would a longer-term experiment reveal inconsistences

143 in responses that would suggest either tempering of bottom-up control by variation in abiotic

144 factors and/or movement of the perturbed community in the direction of a new equilibrium? 


\section{Experimental design}

150 The experiment started two years after CW99 and ran from 1997 through 1999 (hereon

151 designated Years 1, 2, and 3). Each experimental unit (20 in total) was a 2 x 2-m area of forest

152 floor, separated from each other by at least $10 \mathrm{~m}$. Experimental units were randomly assigned to

153 one of two levels of a resource treatment and one of two levels of a fencing treatment, yielding

154 five replicates of each of the four combinations of treatment levels. Thus, half of the units

155 received a detrital supplement (Supplemented), the others none (Ambient), and half of the plots

156 in each resource treatment were open to emigration and immigration (Open), while the others

157 were enclosed with $35-\mathrm{cm}$ aluminum flashing inserted $8 \mathrm{~cm}$ into the ground (Fenced). The fence

158 was topped with a 15-cm horizontal strip of flashing that formed two lips coated on the underside

159 with a tree-banding compound (Tanglefoot ${ }^{\circledR}$, Grand Rapids, Michigan) to further retard

160 movement of epigeic (ground-active) arthropods across the barrier. This design is more complex

161 than that of CW99, which had no fenced plots but employed the same total number of

162 experimental units: twenty 2 x 5-m open plots, half of which received a detrital supplement.

163 We employed the detritus-supplementation protocol of CW99, which has also been used

164 in other experiments (Chen \& Wise 1997; Raub et al. 2014). Our goal was not to determine

165 which components of the resource base (bacteria, fungi, and organic debris) were possibly

166 limiting densities of microbivores and detritivores, as was the aim of Salamon et al. (2006).

167 Rather, our goal was to follow the community response to long-term enhancement of a broadly

168 defined resource base. This experimental approach, including that of Salamon et al. (2006) and

169 others, involves adding artificial forms of organic matter and nutrients. Every two weeks from 
170 April through September we added chopped "fresh" (i.e. not dried) mushrooms and potatoes, and

171 dry flakes of Drosophila medium (Carolina Biological Supply; Burlington, North Carolina,

172 USA; Formula 4-24) to the Supplemented plots.

173 We decided initially to supplement at a rate approximately $1 / 3$ that of CW99 because we

174 hypothesized that the strong responses exhibited in the earlier experiment were due to a high

175 level of detrital enhancement. We planned to continue this rate of supplementation in the

176 following years, but decided to increase the rate because the increase in densities of most taxa in

177 response to the detrital enhancement in Year 1 was much less (including no responses) than that

178 observed by CW99. Therefore, in Years 2 and 3 we increased the rate of supplementation to a

179 level similar to CW99. In Year 1 each Supplemented plot received $195 \mathrm{~g}$ (dry wt.) $\mathrm{m}^{-2}$ of detritus

180 (26 $\mathrm{g} \mathrm{m}^{-2}, 79 \mathrm{~g} \mathrm{~m}^{-2}$ and $90 \mathrm{~g} \mathrm{~m}^{-2}$ of mushrooms, potatoes, and Drosophila medium, respectively).

181 In Years 2 and 3 the rate of detritus supplementation was increased ca. 4x (to $770 \mathrm{~g} \mathrm{~m}^{-2}$ and 874

$182 \mathrm{~g} \mathrm{~m}^{-2}$ total dry wt., respectively). The slightly larger amount of detritus added during Year 3

183 reflects a slightly longer period of detrital addition than in Year 2. Biweekly rates were the same

184 in Years 2 and 3. This change in the rate of resource addition after Year 1 meant that statistical

185 analyses focusing on the Resource x Time interaction only included Years 2 and 3, when rates of

186 resource addition were the same.

187 Adding artificial detritus can influence the structure of the leaf-litter layer, so it is

188 instructive to compare amounts added with litter standing crops. In Year 1 the average $( \pm \mathrm{SE})$

189 standing crop of litter (dry wt. $\left.\mathrm{m}^{-2}\right)$ in Ambient plots was $671 \pm 43 \mathrm{~g}(n=10)$. Thus, the dry

190 weight of detritus added throughout Year 1 was $\sim 30 \%$ of the average standing crop of detritus,

191 compared to an addition rate of $\sim 100 \%$ of the litter standing crop in CW99. In Years 2 and 3

192 each Supplemented plot received $\sim 136 \%$ and $\sim 122 \%$ of that year's average standing crop of 
193 litter, respectively. By the end of Year 3 litter weight was only 13\% higher in Supplemented than

194 Ambient plots $\left(\mathrm{F}_{1,16}=4.93, P=.04\right)$, compared to a $30 \%$ increase at the end of CW99.

195 Due to our decision to increase the supplementation rate in Years 2 and 3 to $\sim 4$ the rate 196 of Year 1, differences in response patterns between Year 1 and the following two years can be 197 attributed not only to differences in abiotic factors between years and time lags in the appearance 198 of direct and indirect effects, but also to markedly different rates of detrital supplementation. In 199 contrast, differences between Years 2 and 3 must have been due primarily to factors other than a 200 difference in the rate of resource addition, since biweekly rates of supplementation in Years 2 201 and 3 were the same.

\section{Fungal biomass}

Differences in fungal abundance between Supplemented and Ambient plots at the end of the experiment were estimated by assaying leaf litter for ergosterol (Supplementary Appendix S1), a common sterol in fungal hyphae that is nearly absent from plants (Weete \& Weber 1980). The amount of ergosterol is correlated with both total hyphal mass and membrane content and likely assayed both living and dead hyphae (Mille-Lindblom et al. 2004; Ruzicka et al. 2000; Zhao et al. 2005).

\section{Arthropods}

214 Selected taxa of arthropods active within and on the surface of leaf litter were sampled three 215 times in Year 1 (18 July, 15 August, 13 October), twice in Year 2 (20 June, 23 September) and 
216 twice in Year 3 (3 June, 5 September). Values for the first two dates in Year 1 were averaged,

217 yielding two values (Summer and Fall) for each year. Densities of most taxa were estimated by

218 litter extraction and/or litter sifting. Sticky traps were used to measure activity-densities of adult

219 flies (Diptera) just above the litter layer.

220

\section{Litter extraction}

222 Densities (measured as number per $.05-\mathrm{m}^{2}$ of forest floor) of 15 taxonomic groupings [six

223 families of springtails (Collembola), thrips (Thysanoptera), larval moths (Lepidoptera), larval

224 and adult beetles (Coleoptera), larval and adult flies (Diptera), pseudoscorpions

225 (Pseudoscorpiones), centipedes (Chilopoda) and spiders (Araneae)] were estimated by taking

226 litter from $.05-\mathrm{m}^{2}$ of forest floor per plot and using a temperature/humidity gradient in a modified

227 Kempson-McFadyen apparatus (Kempson et al. 1963; Schauermann 1982) to extract animals

228 into 50\% ethylene glycol over 10 days. Extracted arthropods were washed and stored in $70 \%$

229 ethyl alcohol until identified.

230

231

\section{Litter sifting}

232 Litter extraction is not the best way to sample densities of active, larger spiders that often are less

233 abundant than smaller life stages and species (Chen \& Wise 1999). Therefore, densities of

234 cursorial spiders (primarily Corinnidae, Clubionidae, Gnaphosidae, and Lycosidae) and web-

235

weaving spiders (primarily Linyphiidae and Dictynidae) were assessed by carefully sifting and

236 searching, in the field, one $0.2-\mathrm{m}^{2}$ sample of litter per plot (different from the $.05-\mathrm{m}^{2}$ sample).

237

238 Sticky traps 
239 Densities (number per $.05-\mathrm{m}^{2}$ ) of larval and adult Diptera within the litter were determined by

240 Kempson extractions. In addition, activity-densities (combined result of density and activity;

241 number captured per trap) of selected families of adult Diptera were assessed with aerial traps

242 placed just above the litter layer. Two $10 \times 10-\mathrm{cm}$ vertical pieces of metal insect screening

243 attached to thin steel rods were coated with Tanglefoot ${ }^{\circledR}$ and placed $0.5 \mathrm{~m}$ apart and

244 perpendicular to each other in each plot for 24 hours.

\section{Taxonomic resolution of response variables}

247 Several criteria dictated the taxonomic resolution of the response variables: (1) a close-as-

248 feasible match to the degree of resolution reported in CW99; (2) logistical constraints (e.g. time

249 and technical help) related to sorting and identifying the number of arthropods collected; (3) the

250 overall pattern of relative abundance (i.e. numbers of each family of Collembola were greater

251 than numbers for each of the other categories, all of which were orders or selected families

252 within orders); and (4) the fact that trophic position (i.e. predator or detritivore) was broadly

253 similar for organisms within orders, with the exception of Coleoptera [CW99 reported total

254 Coleoptera and Staphylinidae, but did not distinguish other families; results were similar in

255 CW99 for total Coleoptera and Staphylinidae)]. Diptera in the litter were fungivorous families.

256 Only fungivorous familes (Mycetophilidae, Sciaridae, and Phoridae) are included in the Diptera

257 numbers from the sticky traps. Note that Diptera adults and spiders each are represented in

258 Kempson samples and also in a different response variable, either sticky traps (Diptera) or litter-

259 sifting (cursorial and web-building spiders). Cursorial and web-building families utilize very

260 different foraging modes (Wise 1993) and could easily be distinguished in sifting samples. They

261 were pooled for Kempson samples due to the challenge of correctly identifying small specimens 
262 to family. Logistical constraints forced us to exclude mites (Acarina), a group that is abundant in

263 leaf litter and was sampled in CW99.

264

265 Statistical analyses

266

Effects of resource addition and fencing were first analyzed for Year 1 to determine how

268 the arthropod community responded to the lower rate of detrital supplementation. We then analyzed responses for Years 2 and 3 using a repeated-measures 2 × 2 × 2 design [Resource (Ambient, Supplemented) x Fencing (Open, Fenced) x Year (2 and 3)]. All statistical modeling was done separately for summer and fall samples (rationale is explained below). The approach just described was used for both multivariate and univariate analyses. Methodological details of the statistical modeling appear in Supplementary AppendixS2. response of the system to resource supplementation change over time? The statistic that directly addresses this question is the Resource $\mathrm{x}$ Year interaction that includes only Years 2 and 3, when the rate of resource input did not vary between years. We evaluated this interaction by relying on a combination of multivariate and univariate statistical techniques. We first used multivariate techniques to determine how detrital supplementation changed arthropod community structure over time and which response variables were most closely linked to these changes. Multivariate analyses were performed first because if there is no multivariate effect, there is no justification

282 for doing separate univariate analyses. Because multivariate effects were present we then conducted independent univariate analyses. This same approach was use to analyze the simple

284 effect of resource supplementation in Year 1. 

summer samples had been exposed to detrital enhancement for fewer months than fall samples and because life histories of many taxa show pronounced seasonal patterns. Initial multivariate analyses of the interaction between [Resource $\mathrm{x}$ Year] and Season confirmed this expectation matrix into summer and fall subsets, yielding one distance matrix for each season. All subsequent multivariate and univariate analyses were done separately for summer and fall samples.

The central logistical question addressed by our field experiment is: How does the openness of the plots affect the observed pattern of responses to detrital supplementation? Thus, we first tested for an interaction between [Resource x Year] and Fencing. If there was no evidence for an interaction ( $P$ value of the 3-way interaction $>.10)$, the design was collapsed (Open and Fenced plots were pooled, yielding twice as many replicates per Resource level) to one involving only Resource and Year. If Fencing possibly influenced the Resource x Year interaction, further analyses were done separately for Open and Fenced plots. Use of $P>.10$

300 (instead of the conventional $P>.05$ criterion) for inferring no interaction with Fencing made it less likely to ignore a weak effect of fencing (due to the relatively low statistical power of only five replicates for each Resource/Fencing combination) that could have influenced interpretation of the response patterns.

\section{Multivariate analyses}

306 Using all 18 response variables, we calculated a distance matrix using Gower's similarity index 307 [S15 of Legendre and Legendre (2012)]. Gower's index was employed because it is designed to 
308 accommodate different types of variables (Kempson, sifting, and sticky-trap samples; Fig. 1).

309 We implemented S15 because this version of Gower's measure is a symmetrical index that gives

310 equal weight to double zeroes (absence/absence) and ++ (presence/presence), which is the type

311 of distance measure philosophically appropriate for analyzing results of a field experiment

312 [unlike the more commonly employed "Bray-Curtis" measure, which is less suited to the

313 assumptions behind controlled manipulative experiments (Legendre \& Legendre 2012)]. Further

314 details are in Supplementary Appendix S2.

315 Permutational multivariate analysis of variance (perMANOVA) (Anderson et al. 2008)

316 was then used to assess the multivariate Resource $\mathrm{x}$ Year interaction. Because our analyses

317 revealed a Resource $\mathrm{x}$ Year interaction, we then assessed the changing impact of Resource on

318 arthropod community structure in two ways. First, we plotted the location of each experimental

319 unit (i.e. 2 x 2-m plot) on the first two axes of the Principal Coordinates Ordination (PCO) for

320 each year along with the $P$ value for the Resource effect each year. Secondly, we evaluated how

321 different response variables contributed to the change in community structure by plotting both

322 simple and multiple correlation vectors on constrained PCO ordinations (CAP; constrained by

323 Resource and Fencing treatments) for each year.

325 Univariate analyses

326 We plotted yearly means $\pm \mathrm{SE}$ of each response variable and then used a range of statistical

327 modelling approaches to help evaluate the change over time in differences between

328 Supplemented and Ambient treatments. Details appear in Supplementary AppendixS2.

330 Overall interpretation of response patterns 
331 Interpretation of how the system responded was accomplished by evaluating the results of

332 multivariate and univariate analyses taken together as a whole. Emphasis was placed upon using

333 the statistical analyses to aid in interpreting the overall patterns of the ordinations and univariate

334 plots. We avoided a completely NHST (Null Hypothesis Significance Testing) approach as much

335 as possible. Thus, we made no corrections for "multiple comparisons" in the univariate analyses,

336 primarily because multivariate effects were clear. Furthermore, we did not conclude that $P$

337 values close to .05 but slightly greater was evidence for the absence of a response

338 (Supplementary Appendix S2). Instead, we relied on $P$ values as a measure of strength of

339 evidence (Cumming 2012; Hector 2015; Nakagawa \& Cuthill 2007). Our overall evaluation of

340 the impact of resource enhancement on the suite of response variables was a melding of (1)

341 changes in community structure as indicated by perMANOVA and PCO, (2) patterns of

342 correlation-vector overlays on constrained ordinations (CAP), (3) univariate effect sizes

343 estimated from plots of numbers for Resource and Ambient treatments over time, and (4) the $P$

344 value of the appropriate statistic - simple Resource effect for Year 1; and for Years 2 and 3, the

345 Resource $x$ Year interaction, or the overall main effect of Resource if there was no change

346 between Years 2 and 3 in the Resource effect.

348 Results

350 Fungal density 
352 Fungal hyphae, as measured by concentrations of ergosterol, were 3x denser in Supplemented

353 than Ambient plots [Supplementary Appendix S1].

354

355 Relative abundance of taxa

356

357 The most abundant taxa were six families of microbi-detritivores (Collembola) collected by

358 Kempson extraction, with the Hypogastruridae, Onychiuridae, and Entomobryidae being the

359 three most numerous (Fig. 1A). Remaining response variables were similar in value to each

360 other, differing by less than 50\%. Centipedes (Chilopoda) were the exception. This predatory

361 taxon had the fewest individuals sampled of all response variables (Fig. 1B).

362

363

Response of arthropods to detrital supplementation

364

365

Results of multivariate analyses are presented first because they constituted the critical first step

366

in the analysis. Results of testing for interactions with Fencing are presented before summarizing

367

evidence for changes in the presence and strength of bottom-up control processes over the three

368

years of the experiment. In each section below, results for Year 1 are presented first, followed

369

by the pattern of change between Years 2 and 3, when the rate of Resource supplementation was

370 the same and was $\sim 4 \mathrm{x}$ higher than in Year 1.

371

372 Multivariate modeling, including univariate vector overlays 
374 Fencing - Permutational multivariate analysis of variance (perMANOVA) uncovered no

375 evidence of an interaction between the openness of a plot and the overall community response to

376 the addition of detritus for either summer or fall (Supplementary Appendix S3) over the course

377 of the experiment. Therefore, Open and Fenced plots were pooled for multivariate analyses of

378 the Resource effect in Year 1 and the Resource $\mathrm{x}$ Year interaction for Years 2 and 3.

379

380

Addition of detritus- In the summer of Year 1 there was no clear divergence in arthropod

community structure between Ambient and Supplemented plots (Fig. 2A, Appendix S4). By fall

the centroids appeared to have diverged slightly more between treatments, but evidence for a

pronounced Resource effect was not strong ( $P=.035$, Fig. 2B, Supplementary Appendix S4).

In contrast, divergence in community structure due to the addition of detritus was clear

for both seasons in Years 2 and 3, as indicated by the small degree of overlap between

communities in Ambient and Resource treatments in ordination space (Fig. 2, Supplementary

3 differed from that of Year $2\left[P\left(\right.\right.$ Pseudo- $F_{1,70}($ Resource $\mathrm{x}$ Year $\left.)\right]=.012$, perMANOVA; Table

S3.2, Supplementary Appendix S3]. Lower dispersion among Ambient plots in the fall of Year 3

(Fig. 2B) is likely causing the Resource $\mathrm{x}$ Year interaction; this is the only time when within-

treatment dispersions in ordination space differed [Fall, Year 3: Pseudo- $F_{1,18}=8.85, P=.007$,

PERMDISP test (Anderson et al. 2008)]. may have been the primary drivers of the observed divergence in community structure (Fig. 3). 
397 time. The pattern of these correlations also differed between seasons. Furthermore, several

398 correlations were negative, indicating the community divergence was not due solely to simple

399 bottom-up control of the response variables.

400

401

402

403

404

405

406

407

408

409

410

411

412

413

414

415

416

417

418

419

\section{Simple Spearman Correlation Coefficients}

Summer -- In the summer of Year 1 the plots were not clearly separated according to detritus treatment, so the vector for isotomid Collembola does not reflect effects of detritus addition (Fig. 3A). In the following two summers, vector patterns reveal bottom-up control of several primary consumers that only weakly reached the secondary-consumer level (Fig. 3A). All response variables with coefficients $\geq .50$ were positively associated with the first axis, which is strongly linked to the detritus-addition treatment. Seven of the ten vectors for Years 2 and 3 represent microbi-detritivores [three for Diptera and four for Collembola (Hypogastruridae, Sminthuridae, and Entomobryidae)]. The remaining three vectors represent simple correlations with larval and adult Coleoptera, which include both predators and microbi-detritivores. Fall -- The pattern for fall samples is more complex (Fig. 3A). Years 1 and 2 exhibited a pattern broadly similar to that of summer samples for Years 2 and 3, although the total number of responding taxa was greater in fall than summer (16 vectors versus 10 , respectively). All vectors were positively correlated with CAP Axis 1 except for Thysanoptera, a consumer of detritus/fungi. Among the other microbi-detritivores, all six Collembola families showed increased densities in the Supplemented treatment in the fall of Year 1 and/or Year 2, as did larval and adult Diptera. More predatory groups had responded to detritus addition in the fall than in the summer. Vectors for both cursorial and web-building spiders in litter-sifting samples were positively associated with the first axis in Year 1 but not Year 2. In Year 2, larval and adult Coleoptera, many of which are predators, responded positively to detritus addition. The pattern 
420 for Year 3 in fall samples is strikingly different. Only two microbi-detritivore groups displayed

421 positive vectors, and one group, larval Lepidoptera, had a weak negative correlation with Axis 1.

422 The strongest correlation in Year 3 was that for web-building spiders. However, the relationship

423 with detrital addition was negative, not positive as was the case in Year 1 (Fig. 3A).

424

425

426

427

428

429

430

431

432

433

434

435

436

437

438

439

440

441

442

\section{Multiple (Partial) Correlation Coefficients}

The multiple (partial) coefficient removes correlations with other response variables (Anderson et al. 2008). Thus, it is not surprising that fewer show a relationship with Axis 1, even with a lower $R^{2}$ threshold, than do vectors representing the simple Spearman statistic (11 vs. 31 vectors, respectively; Fig. 3B vs. Fig. 3A [ignoring Summer of Year 1, when arthropod community structure showed no clear response to adding detritus]). Among the nine multiplecorrelation vectors exhibiting a component positively correlated with Axis 1, only two include some predatory taxa (larval and adult Coleoptera) (Fig. 3B). Among the four vectors that indicate a negative response to detrital supplementation, one is that of a microbi-detritivore (tomocerid Collembola). The other three negative vectors are strictly predatory taxa: pseudoscorpions and total spiders (Ara) in Kempson samples, and web-building spiders (Web) in litter-sifting samples (Fig. 3B).

\section{Univariate statistical modeling}

Plots over time of all 18 response variables appear in Figs. S5.1 - S5.18 in Supplementary Appendix S5. Full results of the statistical modeling of the univariate responses, including a comparison with the vector patterns in Fig. 3, appear in Tables S6.1 - S6.4 in Supplementary Appendix S6. These analyses yield a complicated pattern of responses that is best summarized 
443 pictorially (Fig. 4A; note that Fig. 4A also includes some symbols for vector overlays, which

444 have been excluded from the tallies in the following sections but will be treated in the

445 Discussion).

446

447 Fencing - Although the multivariate analyses uncovered no interactions with Fencing, $30 \%$

448 of the univariate tests that revealed an effect of Resource (10/34; only Chilopoda, the rarest

449 taxon, never responded) exhibited an interaction with the Fencing treatment (Fig. 4A,

450 Supplementary Appendix S6). For most groups the effect was sporadic, i.e. it occurred in only

451 one of the six sampling periods. The two clear exceptions were larval Lepidoptera and

452 pseudoscorpions (Fig. 4A). In both groups an interaction with fencing occurred in three or four

453 sampling periods and always was associated with a decrease in numbers in response to detrital

454 supplementation. The negative Resource effect occurred four times in Open plots, three times in

455 Fenced plots

456

457 Addition of detritus - The pattern of response changed over the three years (Fig. 4A). In

458 Year 1 eleven response variables showed a positive response to detrital addition in at least one

459 season; the only exception was the lower number of Lepidoptera larvae in Open plots in the

460 summer (arrows for vector overlays are not included in this and following tallies). In Year 2

461 eleven response variables also showed a positive response in one or two seasons, but only six of

462 these had displayed a positive response the earlier year. In Year 3 only five variables showed a

463 positive response in summer and/or fall (all had exhibited a positive response the previous year).

464 In Year 2 three variables decreased in response to detrital addition in at least one season and in

465 Year 3 four taxa responded negatively. 
467 detritus) by the fall of Year 1 was transformed the following two years into a mixture of

continued positive responses to detrital addition, disappearance of the early positive responses, appearance of new positive responses, and appearance of negative effects of adding detritus. Individual patterns are presented below by trophic categories.

\section{Fungivores / Detritivores (microbi-detritivores)}

Five of the six Collembola families (first entries of Fig. 4A) displayed evidence of strong bottom-up control, i.e. an effect size of $2 \mathrm{x}$ to $>3 \mathrm{x}$ in at least two seasons over the three years, with the highest number of strong responses in Year 2. Entomobryidae exhibited persistently strong bottom-up control throughout the experiment, with a strong response $(>3 x)$ each fall and weaker but positive responses to detrital addition each summer. The most extreme pattern is that of tomocerid Collembola: a positive response in Fenced plots the fall of Year 1, no response in Year 2, and a negative response in the summer of Year 3. By the fall of Year 3 densities of onychurids, isotomids, tomocerids and sminthurids were close to zero in all plots (Figs. S5.2, S5.4-S5.6 in Supplementary Appendix S6).

Diptera (trapped adults and larvae and adults from Kempson samples) showed positive responses to Resource addition, though responses were sporadic. Larval Diptera displayed the most consistently strong response, particularly in the fall of the last two years. Thysanoptera also responded positively, but only in the first two years.

In marked contrast to the above patterns, larval Lepidoptera displayed a negative, not positive, response to detrital enhancement in five of six sampling periods, but the effect size usually was small and was influenced sporadically by openness of the plots.

\section{Mixed Trophic Levels}


490

491

492

493

494

495

496

497

498

499

500

501

502

503

504

505

506

507

508

509

and 3 but did not respond to the detrital treatment in Year 1. Adult Coleoptera showed a clear response to detrital enhancement only in the fall of Year 2.

\section{Predators}

The Chilopoda (centipedes), the rarest taxon among those sampled (Fig. 1), was the only group to exhibit no response to detrital enhancement during the experiment (Fig. 4A, Supplementary Appendix S6). The other strictly predatory taxa responded, but the direction of the response changed strikingly over the three years. Cursorial spiders in the litter-sifting samples showed a very weak positive response to Resource enhancement in the fall of Year 1, but no response until the fall of Year 3, when they were less abundant in unfenced Supplemented plots than comparable Ambient plots. Total spiders in the Kempson samples were more abundant in detrital-addition plots the first summer, but never differed between Resource treatments during the rest of the experiment. Pseudoscorpions showed no response to detrital enhancement in Year 1, and were less, not more, abundant in Open or Fenced Supplemented plots, compared to comparable Ambient plots, the final four sampling periods. Web-building spiders had exhibited a clear positive response to detrital enhancement by the fall of Year 1, but this response gradually disappeared over the experiment (Fig. S5.17, Supplementary Appendix S5).

Raw Data 
510 The data on which analyses are based can be accessed in Supplementary Appendix S7, which

511 contains a description of the variables in Supplementary Data S8, which contains the raw data

512 and the design variables.

513

514

515 Discussion

516

517 Many ecologists have pointed to the strong positive response to detrital enhancement by both

518 primary consumers and their predators observed by CW99 as evidence of pervasive, strong

519 bottom-up control in terrestrial detritus-based food webs. According to Google Scholar, CW99

520 has been cited frequently - 237 citations as of May 2017 (31 citations in 2015-2017). Our long-

521 term experiment does not support this generalization, particularly with respect to the predators.

522 Fourteen of our 18 response variables are shared with CW99 (Fig. 4). The mixture of outcomes

523 for these shared response variables in our 3-yr experiment contrasts markedly with the strong,

524 bottom-up control observed for all 14 variables in the same forest just a few years earlier in the

525 shorter-term (3.5 mos.) experiment (Fig. 4B vs. Fig. 4A). Only eight of the shared variables [five

526 fungivores/detritivores (microbi-detritivores) and three predators] exhibited bottom-up control in

527 Year 1 of our experiment (considering univariate results and vector overlays for both seasons)

528 and effect sizes also tended to be smaller than in CW99 - a pattern most likely a consequence

529 of our having added detrital resources at 1/3 the rate of CW99. This inference is supported by the

530 fact that in Year 2, when the rate of supplementation was increased 4x to a level slightly higher

531 than that of CW99, all Collembola families except Tomoceridae, and both larval and adult

532 Coleoptera, responded to additional detrital resources is ways very similar to CW99 (Fig. 4). 
533 However, this similarity for the lower trophic levels contrasts sharply with the failure of any

534 strictly predatory group to show an increase in Year 2 of our experiment in response to increased

535 detrital input, in marked contrast with CW99. What is perhaps most surprising about our findings

536 is the complete disappearance of evidence of bottom-up control among predators in the final two

537 years of our study. In fact, during Years 2 and 3 all responses by predator populations to an

538 increased basal resource were negative, not positive. In addition, the overall difference in

539 responses between Year 3 and both Year 2 and CW99 is also striking, especially since rates of

540 detrital supplementation were similar across years.

541 First, we will evaluate possible explanations for why our results are more variable than

542 those of CW99. Then we will weave together our findings and those of CW99 with the variable

543 evidence for bottom-up control in terrestrial food webs revealed by similar field experiments. It

544 will become clear that variation in outcomes reported to date most likely reflects differences

545 between studies in uncontrolled abiotic and biotic environmental factors, amount and nature of

546 the added detrital resource, taxonomic resolution of the response variables, plot size and

547 openness, and duration of the experiment. We will conclude by speculating about new

548 equilibrium states and offering suggestions for future research.

549

550 Comparison with experiment of Chen and Wise 1999 (CW99)

551

552 Fencing and statistical power- Fencing half of our plots meant that we had 10 open plots

553 compared to the 20 open plots of CW99. Thus, when the statistical model included an interaction

554 with Fencing, the number of replicates per Resource treatment was only 5 instead of 10 as in

555 CW99. This reduced statistical power, which occurred in $\sim 30 \%$ of the univariate models, would 
556 have made it more difficult to detect responses to detrital supplementation that were comparable

557 in magnitude to CW99. However, in the remaining $70 \%$ of the univariate models the absence of

558 an interaction with Fencing meant that the statistical power for detecting a Resource effect was

559 comparable to that of CW99. The three instances of a fencing interaction for the microbi-

560 detritivore taxa shared with CW99 (one sampling period each for Hypogastruridae,

561 Tomorceridae and Smithuridae; Fig. 4A) confirmed our expectation that fencing can increase the

562 evidence for bottom-up control, since the positive Resource effect occurred only in the Fenced

563 plots. The barrier may have yielded a greater positive response by reducing emigration, since

564 Collembola are not likely to climb the type of barrier we constructed. The interaction with

565 fencing for Collembola, however, was relatively infrequent; and the direction of the interaction

566 brought the overall pattern of Collembola responses in our experiment closer to those of CW99.

567 Among the primary consumers two other taxa also exhibited a similar interaction with

568 Fencing on one sampling period (Thysanoptera and adult Diptera). Lepidoptera larvae, which

569 were not sampled in CW99, showed a surprising pattern of weak negative responses across the

570 entire experiment peppered with contrasting effects of Fencing (Fig. 4A). The appearance of a

571 negative response at the very start of the experiment, and the fact that no other response variable

572 exhibited a negative response in Year 1, suggests that the pattern is due to a sampling bias that

573 was a consequence of only 5 replicates in each of the 4 treatments.

574 Among predators the interaction between Fencing and Resource was more frequent and

575 variable (i.e. the Resource effect occurred only in Open or Fenced plots with similar frequency).

576 The more variable pattern is likely due to the lower abundances of predators compared to other

577 trophic categories, which would lead to higher overall sampling variation. 
579 showed no consistent pattern for the less-abundant taxa, and for the more abundant microbi-

580 detritivores, the consequence was to bring the overall evidence for bottom-up control closer to

581 that of CW99.

582

583 Plot size - Plot area was 2.5 larger in CW99 than in our experiment $\left(10 \mathrm{~m}^{2}\right.$ versus $\left.4 \mathrm{~m}^{2}\right)$ but the 584 effect of this difference on the possible swamping effect of migration is smaller than the 2.5 ratio 585 might suggest, for three reasons: (1) the rectangular plot shape of CW99 $(2 \times 5 \mathrm{~m})$ means that the 586 perimeter-to-area ratio of our plots was only $1.4 x$ greater than that of CW99 [(8/4)/(14/10]; (2)

587 microbi-detritivores showed a strong response to resource supplementation in open $1-\mathrm{m}^{2}$ plots in 588 an earlier experiment in the same forest (Chen \& Wise 1997); and (3) the absence of consistently 589 strong Fencing x Resource or Fencing x (Resource x Year) interactions suggests that migration 590 across open plot boundaries did not strongly dilute or increase the responses of most taxa to 591 effects of detrital supplementation.

593 Variation in rainfall - Biweekly rates of detrital supplementation were the same in Years 2 594 and 3, yet the patterns of response in both years differed markedly from each other.

595 Furthermore, Year 3 patterns differed markedly from CW99, even though rates of detrital 596 addition in the last two years of our experiment were close to those of CW99. One factor 597 possibly contributing to these differences is year-to-year variation in rainfall, which during Year 5982 of our experiment was close to normal but was $\sim 50 \%$ below normal during Year 3 (Lawrence 599 2000). During CW99 rainfall was 35\% above the long-term average. [In Year 1 rainfall was 600 close to normal (Lawrence 2000), which may explain why several taxa responded positively to 
601 the Resource treatment even though the rate of supplementation was only 1/3 that of CW99.]

602 Higher-than-normal rainfall in the short-term experiment of CW99 may have accelerated fungal

603 growth in the leaf litter, intensifying the effect of the detrital subsidy compared to all three years

604 of our experiment. Furthermore, the much-lower rainfall in Year 3 could explain why densities

605 of four Collembola families - Onychiuridae, Isotomidae, Tomoceridae and Sminthuridae -

606 had declined to near zero in both Ambient and Supplemented plots by the fall of Year 3 (Figs.

607 S5.2, S5.4-S5.6 in Supplementary Appendix S5) (Christiansen 1964; Hopkin 1997; Petersen

608 2002). In contrast to this pattern, however, both hypogastrurid and entomobryiid Collembola

609 responded strongly and positively to Resource supplementation in the fall of Year 3, similarly to

610 the fall of Year 2. Possibly these strong responses occurred despite the low rainfall because of

611 release from competition with the other four Collembola families. Several long-term studies

612 suggest that strong biotic interactions influence Collembola densities, particularly in forests

613 (Chernova \& Kuznetsova 2000; Kampichler \& Geissen 2005; Kuznetsova 2006; Takeda 1987;

614 van Straalen 1985; Vegter 1987; Wolters 1998). However, direct experimental evidence is

615 lacking for resource competition among Collembola families or apparent competition due to

616 shifting pressures from predation.

617

618 Comparison with other experiments testing for bottom-up control in terrestrial

619 detritus-based food webs

620

621 Other experiments usually employed plot sizes comparable to, or smaller than, those we used,

622 and they were conducted for less time. Two exceptions are grassland studies (Fountain et al.

623 (2008, Patrick et al. 2012) in which inorganic nutrients were added for 4 years to very large (240 
624 or 314 sq. m, respectively) unfenced plots. Fountain et al. (2008) found that densities of isotomid

625 Collembola and three spider families increased, but densities of two other spider families

626 decreased, in response to nutrient enhancement. In contrast, Patrick et al. (2012) observed only

627 positive responses by families of web-building and cursorial spiders. In another grassland study

628 that used much smaller (1x1-m) open plots, Hoekman et al. (2011) added midge (Diptera:

629 Chironomidae) carcasses for two years or over a single year starting at different times. As in our 630 study, Collembola, larval Diptera, and Coleoptera exhibited varying positive responses Spiders, 631 however, showed no treatment effect, in contrast to our Year 1 and CW99. Because their plots 632 were just $25 \%$ the area of our experimental units and $10 \%$ that of CW99, movement across plot 633 boundaries could have diluted positive responses by spiders to increased prey. In addition, 634 increased cannibalism and intraguild predation could have contributed to the absence of an effect 635 on total spiders. Oelbermann et al. (2008) directly manipulated energy input to a grassland 636 detrital web in fenced 5- $\mathrm{m}^{2}$ plots for five months. Many Collembola families responded 637 positively as did total spider numbers, which were ca. $2 \mathrm{x}$ higher in the detritus-enhanced plots.

638 Some spider taxa, however, exhibited no numerical response even though stable-isotope analysis 639 revealed that all sampled spiders relied more heavily on the decomposer food web in the detritus640 addition plots. Oelbermann et al. (2008) suggested that even though the secondary-consumer 641 trophic level was strongly linked to the detritus base, individual groups of predators showed 642 inconsistent evidence of bottom-up control due to increased cannibalism and intraguild predation 643 in the plots with additional detritus. Similar interactions could have weakened bottom-up control 644 among predators in Year 1 (with delayed effects in Years 2 and 3), but one still has to explain the 645 strong bottom-up control among predators in CW99. 
647 forests. Scheu and Schaefer (1998) and Maraun et al. (2001) increased microbial growth in the

648 litter layer of fenced $1-\mathrm{m}^{2}$ plots by adding glucose and nitrogen for 15 months with no effect on

649 Collembola or centipedes of the litter layer. In contrast, Collembola and centipedes of the lower

650 soil horizon responded negatively, most likely due to indirect effects of increased earthworm

651 densities (Scheu \& Schaefer 1998; Maraun et al. 2001). We did not sample lower soil layers and

652 in our forest earthworms appeared to be much less abundant than in the German beech forest on

653 limestone (Göttinger Wald) where these studies were conducted (pers. obs., Kentucky and

654 German sites). Also, centipedes were rare in our study, in contrast to the much higher abundance

655 just a few years earlier in CW99 - a difference for which there is no obvious explanation. One

656 might speculate that the rarity of a major predatory group could have altered the pattern of

657 bottom-up control among other predators, but a possible mechanism is illusive.

658 Another explanation for why responses observed by Scheu \& Schaefer (1998) and

659 Maraun et al. (2001) differed from ours is the quite different type of resource enhancement they

660 employed. However, Salamon et al. (2006), who used a similar type of resource enhancement in

661 1-sq. $\mathrm{m}$ fenced plots for 17 months, found that several Collembola families did respond

662 positively with effect sizes similar to those observed in our experiment. Unlike our Year 1,

663 though, spiders did not respond, but the absence of a response by pseudoscorpions does resemble 664 our findings.

665 The forest-floor experiment of Raub et al. (2014) is the closest to ours in technique, as

666 every two weeks for 3 months they added to $1.5 \times 1.5-\mathrm{m}$ unfenced plots the same type of

667 artificial detritus used in CW99 and our study. Collembola numbers responded positively to 
668 resource enhancement, but total predators (spiders, pseudoscorpions, and centipedes combined) 669 did not increase.

670 It is difficult to discern a pattern from such disparate studies, except that the general 671 absence of bottom-up control among predators is similar to our results for Years 2 and 3 (but not 672 for Year 1 nor CW99). Many studies did not employ the same degree of taxonomic resolution 673 employed by us and CW99, which means that the absence of a response for an entire grouping 674 (i.e. Collembola, predators) does not imply that smaller taxonomic categories did not respond 675 positively and/or negatively. We avoided this problem by first using a multivariate approach to 676 examine changes in community structure for a reasonably large number of response variables.

677 Variation between studies in abiotic factors, such as rainfall, could explain some of the 678 differences in outcomes, but that data is generally lacking, or the experiment was usually not 679 conducted for a long enough time for rainfall differences to appear. The openness of the plots, 680 especially for those that were smaller than those in CW99, could explain some of the variable 681 responses. Our 3-year experiment, with open and fenced plots and the ability to compare directly 682 with CW99, overcomes many of these challenges to interpretation.

683

Towards a deeper understanding of bottom-up control in detrital food webs

685

686 Some of the weakening of bottom-up control between Years 2 and 3 in our experiment can be 687 explained by $50 \%$ less rainfall in Year 3. In detrital food webs a weak positive response by 688 microbi-detritivores to resource addition is expected if drought impedes fungal growth.

689 However, lower rainfall, although a likely contributing factor, cannot entirely explain the weaker 690 bottom-up control in Year 3. Fungal hyphae were still 3x more abundant in Supplemented than 
691 Ambient plots in Year 3 (Supplementary Appendix S1), and the total amount of detrital material 692 (leaf litter plus added detritus) at the end of Year 3 was only 13\% greater in Supplemented than 693 Ambient plots, compared to a 30\% difference for CW99, when rainfall was higher than any 694 year of our experiment. Thus, fungal growth may still have been substantial in Year 3. Although 695 drier conditions in the litter could explain why densities of four Collembola families were close 696 to zero in all plots in the fall (and hence failed to exhibit bottom-up control), not all primary 697 consumers exhibited a fall crash in Year 3 (Supplementary Appendix S5). In addition, 698 examination of changes in numbers all Collembola families during the summer reveals no 699 correlation with changes in rainfall over the three years of the experiment. Most critically, 700 declining rainfall cannot readily explain the negative responses to detrital supplementation. Why was one major Collembola family, the Tomoceridae, less abundant in Supplementation than Ambient plots in Year 3? In this forest predation by cursorial spiders depresses tomocerid densities (Wise 2004), but cursorial spiders were less, not more, abundant in the Supplementation treatment in Year 3. In fact, the widespread negative responses of predators to detrital addition the last two years was surprising when compared with CW99 and other studies. It is unclear how all these negative responses could result from shifting intensities of intraguild predation and cannibalism in response to increased abundances of microbi-detritivores. Possibly contributing factors are declining numbers of high-quality prey (Tomoceridae) (Toft $\&$ Wise 1999b) and increased densities of possibly toxic isotomid (Toft \& Wise 1999a; Toft \& Wise 1999b) and hypogastrurid prey (Messer et al. 2000; Negri 2004) in Years 2 and/or 3 in the

711 Supplemented plots. It is difficult to evaluate the solidity of such post-hoc theorizing without 712 additional information. 
714 supplementation by predators and tomocerids, variation in community structure between

715 Supplemented plots was greater than between Ambient plots the fall of Year 3 - the only

716 sampling period that displayed this difference (Fig. 2). This increased variation in community

717 structure after three years, and all the unexpected contrasts of the univariate analyses with

718 CW99, suggest that that long-term resource supplementation will lead to a community

719 configuration that cannot be predicted from initial short-term population responses. On the other

720 hand, could such negative responses in long-term experiments simply be random vagaries

721 emerging from the low replication in most field experiments? Or might they be the surprising

722 results that ecologists often fail to report (Doak et al. 2008) - the unexpected observations that

723 can help build stronger theory? Additional long-term experiments will help resolve this dilemma.

724 How long is long enough? The behavior of mathematical models of long-term press

725 perturbations suggests that many generations will be required to reach a new equilibrium

726 (Bender et al. 1984; Raffaelli \& Moller 2000; Yodzis 1988), which coupled with environmental

727 noise, such as variation in rainfall, might make the prospects of a "long-enough" field

728 experiment seem hopeless. However, after reviewing short- and long-term experiments (2 to 31

729 mos.) in the intertidal, Menge (1997) concluded that “. . . community dynamics may be more

730 predictable than expected ..." because most indirect effects had appeared half-way through the

731 experiment. "Long enough" is at least the number of generations sufficient to reveal indirect

732 effects. An even longer time would reveal how close the community may be to a new

733 equilibrium. This longer time will never be achieved with certainty, but snapshots yielded by

734 short-term experiments cannot answer the question. 

experiments we need to reduce the impact of unpredictable and unknown variation in other

737 factors. Furthermore, we must have a deeper understanding of which interaction pathways were altered in response to resource supplementation. How might these two challenges be met? The challenge of accounting for uncontrollable yearly variation in abiotic and biotic factors can be addressed by expanding the experimental design to include initiation of resource additions in new sets of experimental units in each subsequent year after the experiment has started, along with continuing the experimental treatment in the plots from the first year. Phased temporal replication of the experimental perturbation offers the surest way of clearly separating effects due to time lags from those due to changing levels of unknown but influential abiotic and biotic factors. Hoekman et al. (2011) employed a preliminary but elegant version of this approach by combining two yearly pulse treatments of detritus addition with a two-year press treatment.

The second challenge can be met in several ways. One is the use of path analysis and structural equation modeling to help separate direct and indirect effects among interaction pathways between taxa in major trophic groupings in the food web (Grace 2006; Wootton 1994). However, this statistical modeling approach requires numerous replicates, more than are possible with most types of detrital enhancement experiments performed to date. Tradeoffs between toomany response variables, too-few replicates, and experimental units too small to be realistic present daunting challenges. Another approach is to measure more variables than just the densities of primary consumers and their predators. Molecular techniques are available to measure different functional categories of fungi (Nguyen et al. 2016; Shokralla et al. 2012). Shifts in major trophic pathways can be revealed by techniques such as stable isotopes and fatty 
758 acid analysis (Halaj \& Wise 2002; Ruess et al. 2004), and PCR of prey DNA in guts of predators

759 such as spiders and carabids (Harper et al. 2005; Symondson 2002).

760 Some of the above suggestions already have been incorporated into short-term field

761 experiments testing for bottom-up control in detritus-based terrestrial food webs. Utilizing all of

762 them in a single study is a challenge. Nevertheless, paying heed to their advantages when

763 planning future long-term research would help reveal likely causes of the type of variability

764 found in our 3-yr experiment.

765

766 Acknowledgements

767

768 We thank Berea College for permission to conduct the research in the Berea College Forest.

769 Keith Erny, Sara Todd, Meredith Houston, Tom Coleman, and Adam Keener provided field and 770 laboratory assistance; and Lowell Bush and Neil Fannin provided valuable help with use of

771 HPLC to assay for ergosterol. Suggestions of Robin Mores, Matthew McCary, Monica Farfan,

772 Crystal Guzmán, Christian Mulder, Daniel Grunder, Shaun Turney, and anonymous reviewers 773 greatly improved the manuscript.

774

775

776

777

778

779

780

Anderson MJ, Gorley RN, and Clarke KR. 2008. PERMANOVA+ for PRIMER: Guide to Software and Statistical Methods. Plymouth, UK: PRIMER-E Ltd.

Bardgett RD, and Wardle DA. 2010. Aboveground-Belowground Linkages: Biotic Interactions, Ecosystem Proceses, and Global Change. Oxford, UK: Oxford University Press. 
781 Bender EA, Case TJ, and Gilpin ME. 1984. Perturbation experiments in community ecology:

782 Theory and practice. Ecology 65:1-13. http://dx.doi.org/10.2307/1939452

783 Chen BR, and Wise DH. 1997. Responses of forest-floor fungivores to experimental food 784 enhancement. Pedobiologia 41:316-326.

785 Chen BR, and Wise DH. 1999. Bottom-up limitation of predaceous arthropods in a detritus786

787

Chernova NM, and Kuznetsova NA. 2000. Collembolan community organization and its temporal predictability. Pedobiologia 44:451-466. http://dx.doi.org/10.1078/s0031$\underline{4056(04) 70063-3}$

Christiansen K. 1964. Bionomics of Collembola. Annual Review of Entomology 9:147-178.

Cumming G. 2012. The New Statistics: Effect Sizes, Confidence Limits, and Meta-Analysis. New York: Routledge.

David J-F, Ponge J-F, Arpin P, and Vannier G. 1991. Reactions of the macrofauna of a forest mull to experimental perturbations of litter supply. Oikos 61:316-326. http://dx.doi.org/ $10.2307 / 3545239$

Doak DF, Estes JA, Halpern BS, Jacob U, Lindberg DR, Lovvorn J, Monson DH, Tinker MT, Williams TM, Wootton JT, Carroll I, Emmerson M, Micheli F, and Novak M. 2008. Understanding and predicting ecological dynamics: Are major surprises inevitable? Ecology 89:952-961. http://dx.doi.org/10.1890/07-0965.1

Fountain MT, Brown VK, Gange AC, Symondson WOC, and Murray PJ. 2008. Multitrophic effects of nutrient addition in upland grassland. Bulletin of Entomological Research 98:283-292. http://dx.doi.org/10.1017/s000748530700555x 
804 Gardner RH, Kemp WM, Kennedy VS, and Petersen JE. 2004. Scaling Relations in 805 Experimental Ecology. New York, NY: Columbia University Press.

806 Grace JB. 2006. Structural Equation Modeling and Natural Systems. New York: Cambridge $807 \quad$ University Press.

808 Hairston NG. 1989. Ecological Experiments: Purpose, Design, and Execution. Cambridge, UK: 809 Cambridge University Press.

810 Hairston NG, Jr., and Hairston NG, Sr. 1993. Cause-effect relationships in energy-flow, trophic 811 structure, and interspecific interactions. American Naturalist 142:379-411.

$812 \quad$ http://www.jstor.org/stable/2462650

813 Halaj J, and Wise DH. 2002. Impact of a detrital subsidy on trophic cascades in a terrestrial 814 grazing food web. Ecology 83:3141-3151. http://dx.doi.org/10.2307/3071849

815 Harper GL, King RA, Dodd CS, Harwood JD, Glen DM, Bruford MW, and Symondson WOC. 816 2005. Rapid screening of predators for multiple prey DNA targets. Molecular Ecology 14:819-827. http://dx.doi.org/ 10.1111/j.1365-294x.2005.02442.x

818 Hector A. 2015. The New Statistics with R: An Introduction for Biologists. Oxford: Oxford $819 \quad$ University Press.

820

821

822

823 824 825 826

Hoekman D, Dreyer J, Jackson RD, Townsend PA, and Gratton C. 2011. Lake to land subsidies: Experimental addition of aquatic insects increases terrestrial arthropod densities. Ecology 92:2063-2072. http://www.jstor.org/stable/23034939

Hopkin SP. 1997. Biology of the springtails (Insecta, Collembola). New York: Oxford University Press.

Hurlbert SH. 1984. Pseudoreplication and the design of ecological field experiments. Ecological Monographs 54:187-211. http://dx.doi.org/ 10.2307/1942661 
827 Kajak A. 1997. Effects of epigeic macroarthropods on grass litter decomposition in mown

828

829

830

831

832

833

834

835

836

837

838

839

840

841

842

843

844

845

846

847

848

849

meadow. Agriculture, Ecosystems and Environment 64:53-63. http://dx.doi.org/ $10.1016 / \mathrm{S} 0167-8809(96) 01125-5$

Kajak A, and Jakubczyk H. 1977. Experimental studies on predation in the soil-litter interface. EcolBull, Stockholm 25:493-496.

Kampichler C, and Geissen V. 2005. Temporal predictability of soil microarthropod communities in temperate forests. Pedobiologia 49:41-50. http://dx.doi.org/10.1016/j.pedobi.2004.07.011

Kempson D, Lloyd M, and Ghelardi R. 1963. A new extractor for woodland litter. Pedobiologia $3: 1-21$.

Kuznetsova NA. 2006. Long-term dynamics of Collembola in two contrasting ecosystems. Pedobiologia 50:157-164. http://dx.doi.org/10.1016/j.pedobi.2005.12.004

Lawrence KL, and Wise DH. 2004. Unexpected indirect effect of spiders on the rate of litter disappearance in a deciduous forest. Pedobiologia 48:149-157. http://dx.doi.org/10.1016/j.pedobi.2003.11.001

Legendre P, and Legendre L. 2012. Numerical Ecology. Oxford, UK: Elsevier.

Lensing JR, and Wise DH. 2006. Predicted climate change alters the indirect effect of predators on an ecosystem process. Proceedings of the National Academy of Sciences of the United States of America 103:15502-15505. http://dx.doi.org/10.1073/pnas.0607064103

Lessard JP, Sackett TE, Reynolds WN, Fowler DA, and Sanders NJ. 2011. Determinants of the detrital arthropod community structure: the effects of temperature and resources along an environmental gradient. Oikos 120:333-343. http://dx.doi.org/10.1111/j.16000706.2010.18772.x 
850 Maraun M, Alphei J, Beste P, Bonkowski M, Buryn R, Migge S, Peter M, Schaefer M, and

851

852

853

854

855

856

857

858

859

860

861

862

863

864

865

866

867

868

869

870

Scheu S. 2001. Indirect effects of carbon and nutrient amendments on the soil meso- and microfauna of a beechwood. Biology and Fertility of Soils 34:222-229. http://dx.doi.org/ $10.1007 / \mathrm{s} 003740100403$

McCann KS. 2012. Food Webs. Princeton, NJ: Princeton University Press.

Menge BA. 1997. Detection of direct versus indirect effects: Were experiments long enough? American Naturalist 149:801-823. http://dx.doi.org/10.1086/286025

Menge BA. 2000. Top-down and bottom-up community regulation in marine rocky intertidal habitats. Journal of Experimental Marine Biology and Ecology 250:257-289. http://dx.doi.org/10.1016/s0022-0981(00)00200-8

Messer C, Walther J, Dettner K, and Schulz S. 2000. Chemical deterrents in podurid Collembola. Pedobiologia 44:210-220. http://dx.doi.org/10.1078/S0031-4056(04)70041-4

Mille-Lindblom C, von Wachenfeldt E, and Tranvik LJ. 2004. Ergosterol as a measure of living fungal biomass: persistence in environmental samples after fungal death. Journal of Microbiological Methods 59:253-262. http://dx.doi.org/10.1016/j.mimet.2004.07.010

Moore JC, Berlow EL, Coleman DC, de Ruiter PC, Dong Q, Hastings A, Johnson NC, Mccann KS, Melville K, Morin PJ, Nadelhoffer K, Rosemond AD, Post DM, Sabo JL, Scow KM, Vanni MJ, and Wall DH. 2004. Detritus, trophic dynamics and biodiversity. Ecology Letters 7:584-600. http://dx.doi.org/ 10.1111/j.1461-0248.2004.00606.x

Moore JC, and deRuiter PC. 2012. Energetic Food Webs: An Analysis of Real and Model Ecosystems. Oxford, UK: Oxford University Press. 
871 Nakagawa S, and Cuthill IC. 2007. Effect size, confidence interval and statistical significance: a 872 practical guide for biologists. Biological Reviews 82:591-605.

873 http://dx.doi.org/10.1111/j.1469-185X.2007.00027.x

874 Negri I. 2004. Spatial distribution of Collembola in presence and absence of a predator. Pedobiologia 48:585-588. http://dx.doi.org/10.1016/j.pedobi.2004.07.004

876

877

878

879

880

881

882

883

884

885

886

887

888

889

890

891

892

893

Nguyen NH, Song ZW, Bates ST, Branco S, Tedersoo L, Menke J, Schilling JS, and Kennedy PG. 2016. FUNGuild: An open annotation tool for parsing fungal community datasets by ecological guild. Fungal Ecology 20:241-248. http://dx.doi.org/10.1016/j.funeco.2015.06.006

Oelbermann K, Langel R, and Scheu S. 2008. Utilization of prey from the decomposer system by generalist predators of grassland. Oecologia 155:605-617. http://dx.doi.org/10.1007/s00442-007-0927-4

Osenberg CW, and Mittelbach GG. 1996. The relative importance of resource limitation and predator limitation in food chains. In: Polis GA, and Winemiller KO, eds. Food Webs: Integration of Patterns and Dynamics. New York: Chapman and Hall, 134-148.

Patrick LB, Kershner MW, and Fraser LH. 2012. Epigeal spider responses to fertilization and plant litter: testing biodiversity theory at the ground level. Journal of Arachnology 40:309-324. http://www.jstor.org/stable/41758980

Petersen H. 2002. General aspects of collembolan ecology at the turn of the millennium. Pedobiologia 46:246-260. http://dx.doi.org/10.1016/s0031-4056(04)70140-7

Pimm SL. 2002. Food webs. Chicago: University of Chicago Press.

Polis GA, and Strong DR. 1996. Food web complexity and community dynamics. American Naturalist 147:813-846. http://dx.doi.org/ 10.1086/285880 
894 Polis GA, Winemiller, K.O. 1996. Food Webs: Integration of Patterns and Dynamics. New York: $895 \quad$ Chapman and Hall. p 472.

896 Raffaelli D, and Moller H. 2000. Manipulative field experiments in animal ecology: Do they 897 promise more than they can deliver? Advances in Ecological Research, Vol 30 30:299-

898 338. http://dx.doi.org/ 10.1016/S0065-2504(08)60020-3

899

900

901

902

903

904

905

906

907

908

909

910

911

912

913

914

915

Raub F, Scheuermann L, Hofer H, and Brandl R. 2014. No bottom-up effects of food addition on predators in a tropical forest. Basic and Applied Ecology 15:59-65. http://dx.doi.org/10.1016/j.baae.2013.12.001

Resetarits J, W. J., Bernardo, J. 1998. Experimental Ecology: Issues and Perspectives. Oxford: Oxford University Press. p 470.

Ruess L, Haggblom MM, Langel R, and Scheu S. 2004. Nitrogen isotope ratios and fatty acid composition as indicators of animal diets in belowground systems. Oecologia 139:336346. http://dx.doi.org/ 10.1007/s00442-004-1514-6

Ruzicka S, Edgerton D, Norman M, and Hill T. 2000. The utility of ergosterol as a bioindicator of fungi in temperate soils. Soil Biology and Biochemistry 32:989-1005. http://dx.doi.org/10.1016/S0038-0717(00)00009-2

Salamon JA, Alphei J, Ruf A, Schaefer M, Scheu S, Schneider K, Suhrig A, and Maraun M. 2006. Transitory dynamic effects in the soil invertebrate community in a temperate deciduous forest: Effects of resource quality. Soil Biology \& Biochemistry 38:209-221. http://dx.doi.org/10.1016/j.soilbio.2005.04.033

Schauermann J. 1982. Verbesserte Extraktion der terrestrischen Bodenfauna im Vielfachgeraet modifiziert nach Kempson und Macfayden. Okosysteme auf Kalkgestein 135:47-50. 
916 Scheu S, and Schaefer M. 1998. Bottom-up control of the soil macrofauna community in a 917 beechwood on limestone: Manipulation of food resources. Ecology 79:1573-1585. 918 http://www.jstor.org/stable/1767773

919 Shokralla S, Spall JL, Gibson JF, and Hajibabaei M. 2012. Next-generation sequencing 920 technologies for environmental DNA research. Molecular Ecology 21:1794-1805.

921 http://dx.doi.org/10.1111/j.1365-294X.2012.05538.x

922

Symondson WOC. 2002. Molecular identification of prey in predator diets. Molecular Ecology

923 11:627-641. http://dx.doi.org/ 10.1046/j.1365-294X.2002.01471.x

924

925

926

927

928

929

930 931

932

933

934

935

936

937 938

Takeda H. 1987. Dynamics and maintenance of collembolan community structure in a forest soil system. Researches on Population Ecology 29:291-346. http://dx.doi.org/ 10.1007/BF02538892

Toft S, and Wise DH. 1999a. Behavioral and ecophysiological responses of a generalist predator to single- and mixed-species diets of different quality. Oecologia 119:198-207. http://www.jstor.org/stable/4222296

Toft S, and Wise DH. 1999b. Growth, development, and survival of a generalist predator fed single- and mixed-species diets of different quality. Oecologia 119:191-197. http://www.jstor.org/stable/4222295

van Straalen NM. 1985. Comparative demography of forest floor Collembola populations. Oikos 45:253-265. http://dx.doi.org/10.2307/3565712

Vegter JJ. 1987. Phenology and seasonal resource partitioning in forest floor Collembola. Oikos 48:175-185. http://dx.doi.org/10.2307/3565853

Wardle DA. 2002. Communities and Ecosystems: Linking the Aboveground and Belowground Components. Princeton, NJ: Princeton University Press. 
939 Weete JD, and Weber DJ. 1980. Lipid biochemistry of fungi and other organisms. New York:

$940 \quad$ Plenum Publishing.

941 Wise DH. 2004. Wandering spiders limit densities of a major microbi-detritivore in the forest-

942 floor food web. Pedobiologia 48:181-188. http://dx.doi.org/10.1016/j.pedobi.2003.12.001

943 Wise, DH. 1993. Spiders in Ecological Webs. Cambridge, UK: Cambridge University Press.

944 Wolters V. 1998. Long-term dynamics of a collembolan community. Applied Soil Ecology

945 9:221-227. http://dx.doi.org/10.1016/s0929-1393(98)00079-1

946 Wootton JT. 1994. Predicting direct and indirect effects: an integrated approach using

947 experiments and path analysis. Ecology 75:151-165. http://dx.doi.org/ 10.2307/1939391

948 Yang LH. 2006. Interactions between a detrital resource pulse and a detritivore community.

949 Oecologia 147:522-532. http://dx.doi.org/10.1007/s00442-005-0276-0

950 Yodzis P. 1988. The indeterminacy of ecological interactions as perceived through perturbation

$951 \quad$ experiments. Ecology 69:508-515. http://dx.doi.org/10.2307/1940449

952 Zhao XR, Lin Q, and Brookes PC. 2005. Does soil ergosterol concentration provide a reliable

953 estimate of soil fungal biomass? Soil Biology and Biochemistry 37:311-317.

954 http://dx.doi.org/10.1016/j.soilbio.2004.07.041

955 Zuur AF, Ieno EN, Walker NJ, Saveliev AA, and smith GM. 2009. Mixed effects models and

956 extension in ecology with R. New York, NY: Springer. 
957 Figures 1-4 

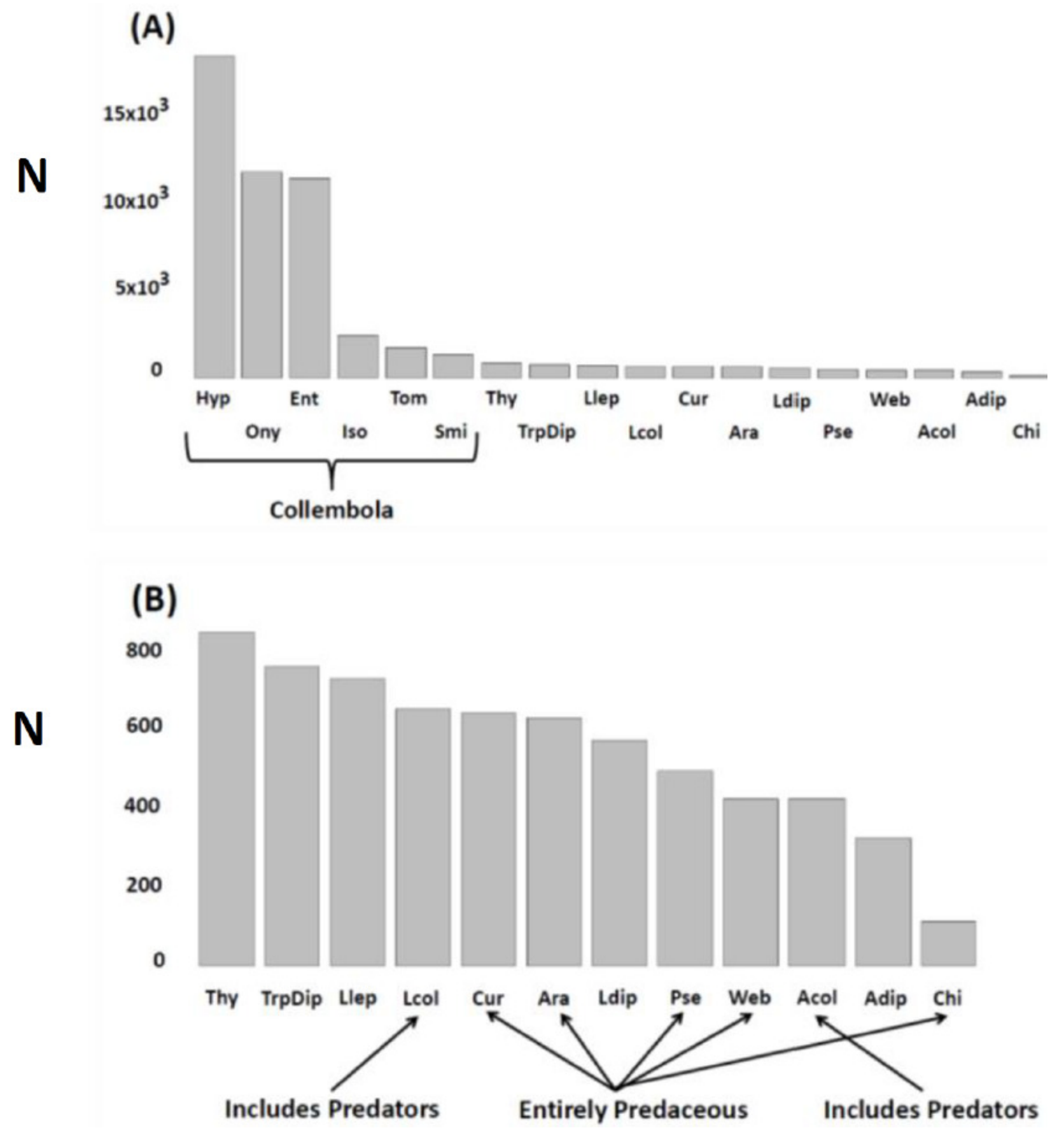

958 Figure 1. N (ordinate) = total number extracted, encountered in litter sifting, or trapped during 959 the experiment. Response variables (combinations of taxa and sampling methods) pooled across 960 treatments, seasons. and years. (A) All response variables $(N=18)$; (B) Non-Collembola 
961 response variables $(N=12)$. Variables are arranged in descending order of abundance. Key to

962 abbreviations is based upon the three different sampling techniques. KEMPSON: Collembola

963 (springtails) -- Hyp $=$ Hypogastruridae, Ony $=$ Onychiuridae, Ent $=$ Entomobryidae, Iso $=$

964 Isotomidae, $\mathbf{T o m}=$ Tomoceridae, $\mathbf{S m i}=$ Sminthuridae; Thy $=$ Thysanoptera $($ thrips $) ;$ Llep $=$

965 larval Lepidoptera (moths); Lcol = larval Coleoptera (beetles); Ara = Araneae (total spiders);

966 Ldip = larval Diptera (flies); Pse = Pseudoscorpiones $;$ Acol = adult Coleoptera (beetles); Adip

967 = adult Diptera (flies); Chi = Chilopoda (centipedes). LITTER SIFTING: Cur = cursorial

968 spider families (primarily Corinnidae, Clubionidae, Gnaphosidae and Lycosidae); Web = web-

969 weaving spider families (primarily Linyphiidae and Dictynidae). STICKY TRAPS: TrpDip =

970 adult Diptera (flies). Note that estimates of spider densities and adult Diptera numbers (density

971 and activity-density) come from two different sampling methods.

972 

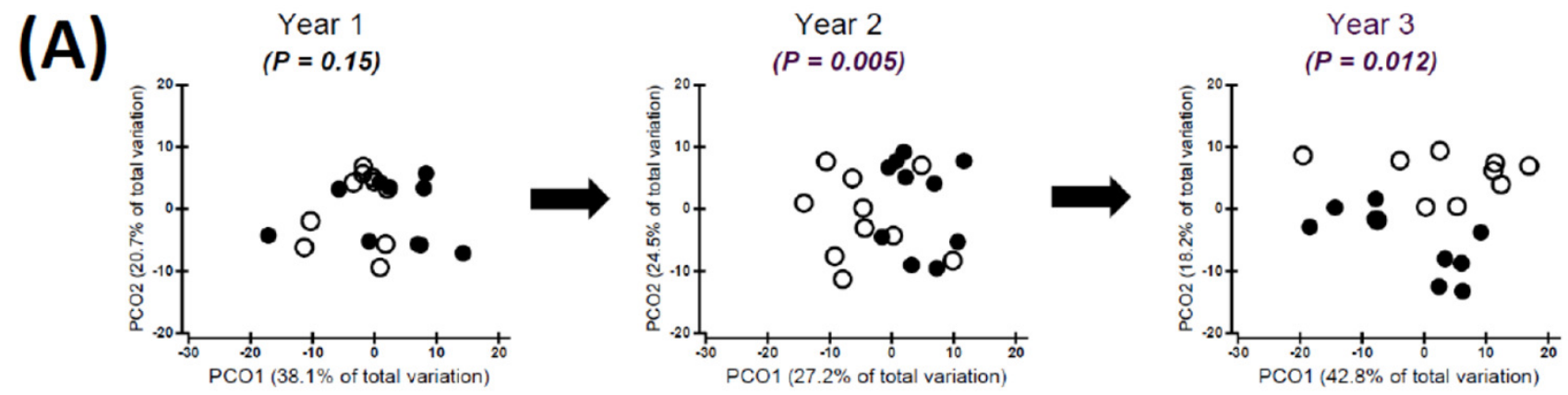

(B)
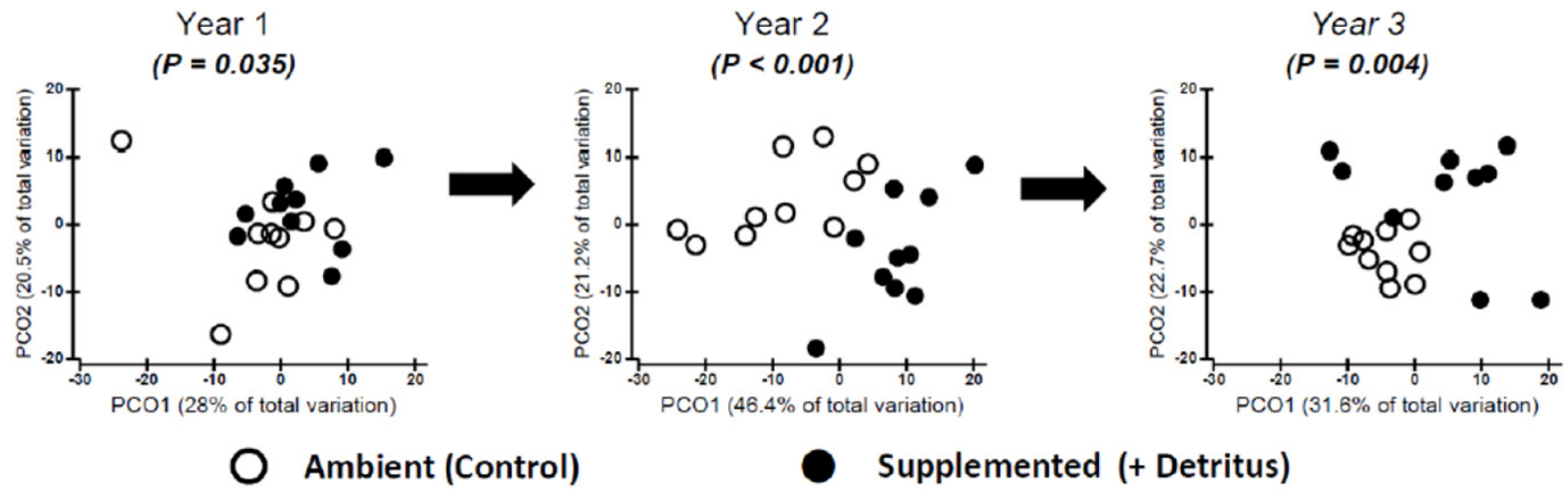

973 Figure 2. Changing impact over time of detritus addition upon arthropod community structure.

974 Principal Coordinates Ordinations (PCO on Gower's distance measure; Supplementary

975 Appendix S2) presented separately for (A) SUMMER and (B) FALL. Open and Fenced plots

976 have been pooled because there were no interactions involving (Resource $\mathrm{x}$ Year) and Fencing

977 (Tables S3.1 and S3.2 in Supplementary Appendix S3). P-values for the Resource treatment are

978 given for each Year. Biweekly rates of detritus addition were the same in Years 2 and 3 and were

$979 \sim 4 x$ higher than in Year 1. The effect of Resource addition on community structure varied between Years 2 and $3[P($ Resource x Year $)=.012$, Table S3.2 in Supplementary Appendix S3]. 
(A)
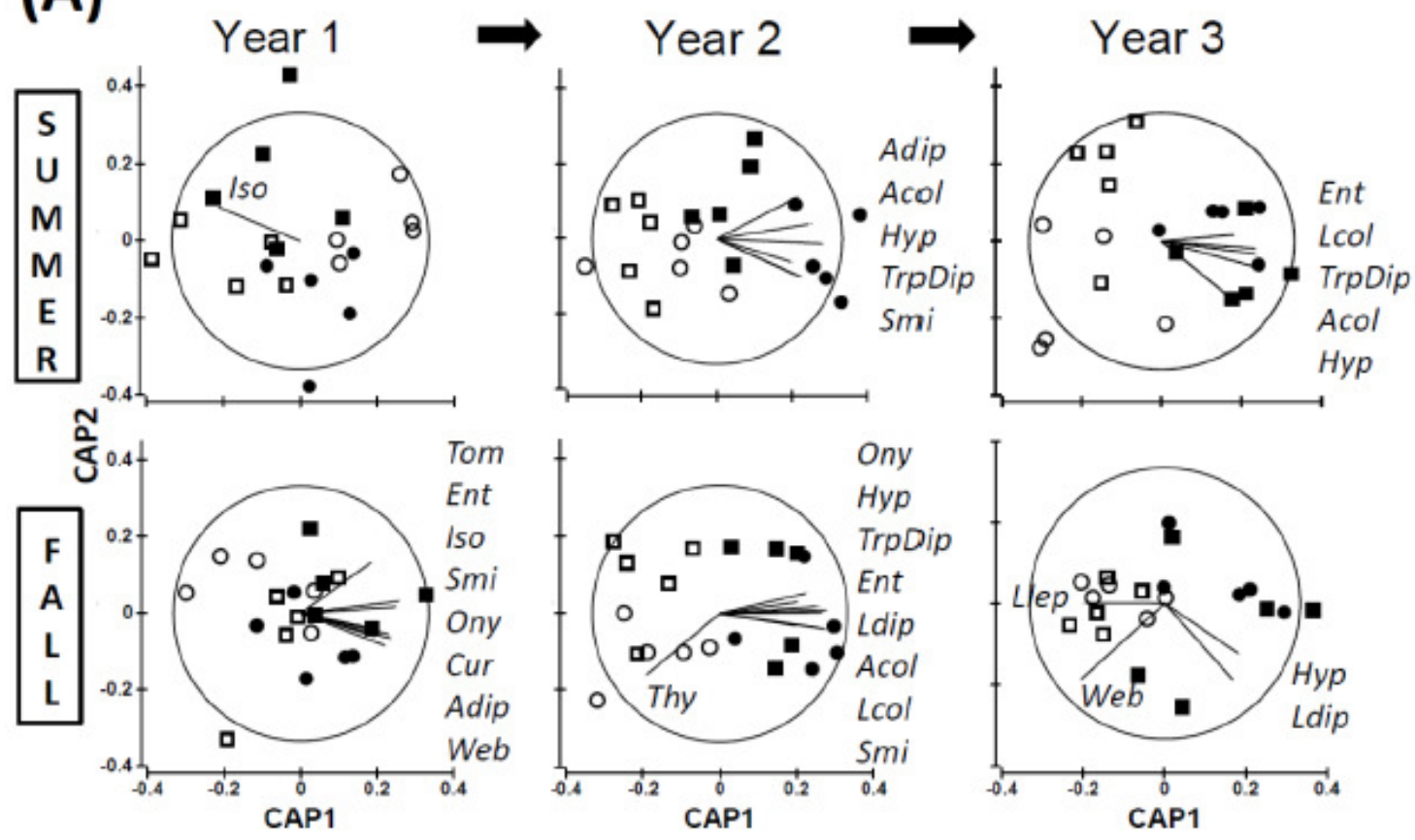

Open
Open + Detritus
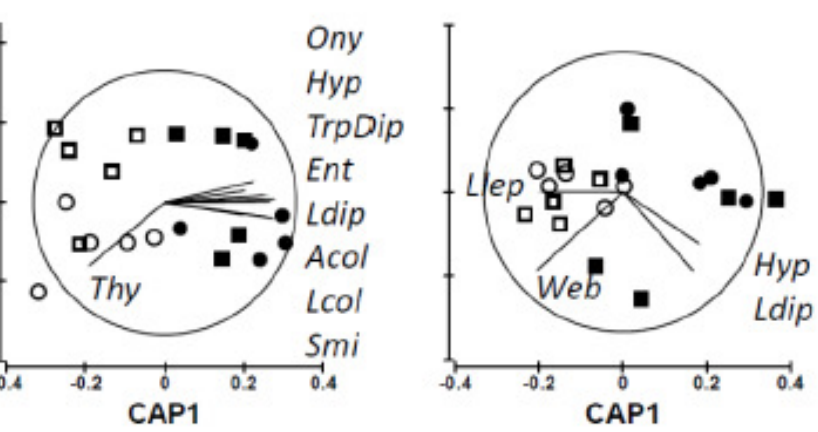

Fenced

Fenced + Detritus

(B)

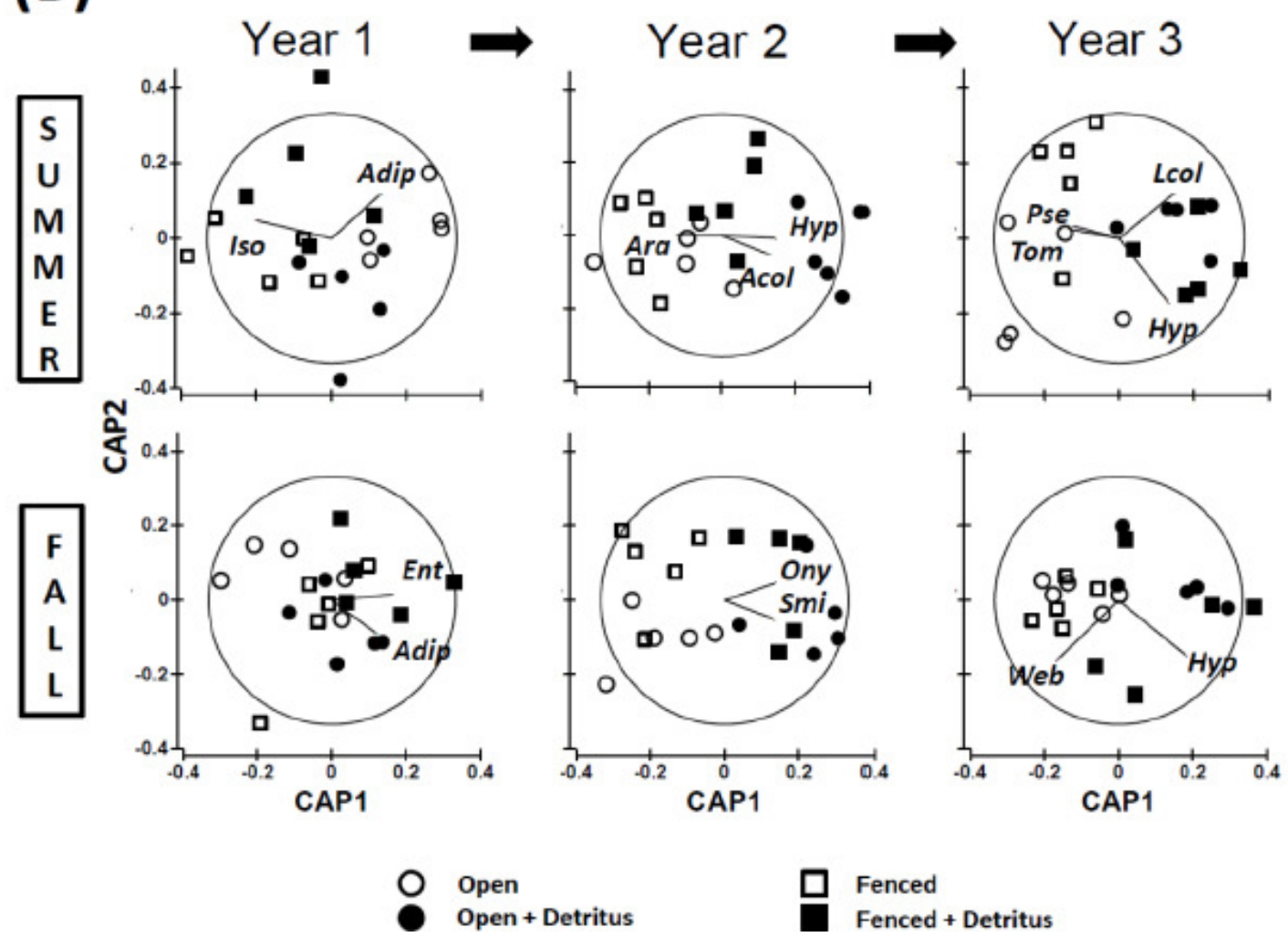

982 Figure 3. (A) Constrained ordination (CAP; Resource and Fencing are the constraining factors)

983 with vector overlays representing simple Spearman correlations between response variables and 
984 the two axes (Supplementary Appendix S2). Separation of communities along Axis 1 is largely

985 related to the impact of the Resource treatment on community structure. Thus, the extent to

986 which a vector is parallel with Axis 1 reflects the extent of the negative (to the left) or positive

987 (to the right) correlation of densities of that taxon with the addition of detritus. The length of

988 each vector represents the joint correlation of the response variable with both axes of the

989 ordination, with the circle representing a correlation of 1. Vectors shown have Spearman

990 coefficients with CAP Axis 1 that are $\geq .50$ or $\leq-.50$. To prevent clutter on the graph, arrow

991 heads of the vectors are not drawn. Key to abbreviations is in Fig. 1. (B) Constrained ordination

992 (CAP) with vector overlays representing multiple correlation coefficients (analogous to

993 univariate partial correlation coefficients).

994 


\begin{tabular}{|c|c|c|c|c|c|c|c|}
\hline \multirow{3}{*}{$\begin{array}{l}\text { Trophic Category : } \\
\text { Taxonomic Category }\end{array}$} & \multicolumn{6}{|c|}{$\begin{array}{l}\text { (A) Temporal Response Pattern: } \\
\text { Size and Direction of } \Delta \text { Resource Effect }\end{array}$} & \multirow{3}{*}{$\begin{array}{c}\text { (B) } \\
\text { Chen \& } \\
\text { Nise (1999) } \\
\text { FALL }\end{array}$} \\
\hline & \multicolumn{2}{|c|}{ YEAR 1} & \multicolumn{2}{|c|}{ YEAR 2} & \multicolumn{2}{|c|}{ YEAR 3} & \\
\hline & Summer & FALL & Summer & FALL & Summer & FALL & \\
\hline \multicolumn{8}{|l|}{ Fungivores/Detritivores: } \\
\hline \multicolumn{8}{|l|}{ Hypogastruridae (Hyp) } \\
\hline \multicolumn{8}{|l|}{ Onychuridae (Ony) } \\
\hline \multicolumn{8}{|l|}{ Entomobryidae (Ent) } \\
\hline \multicolumn{8}{|l|}{ Isotomidae (Iso) } \\
\hline \multicolumn{8}{|l|}{ Tomoceridae (Tom) } \\
\hline \multicolumn{8}{|l|}{ Sminthuridae (Smi) } \\
\hline \multicolumn{7}{|l|}{ Thysanoptera (Thy) } & N/A \\
\hline Diptera (Trapped) (TrpDip) & & & $(*)$ & & $(*)$ & $(*)$ & $+4 *$ \\
\hline Lepidoptera Larvae (Llep) & $\cdots 0$ & & $(*) 0$ & *** & $\sqrt{* *} \mathrm{~F}$ & ** & N/A \\
\hline \multicolumn{7}{|l|}{ Larval Diptera (Ldip) } & N/A \\
\hline \multicolumn{7}{|l|}{ Adult Diptera (Adip) } & N/A \\
\hline \multicolumn{8}{|l|}{ Mixed Trophic Levels: } \\
\hline \multicolumn{8}{|l|}{ Larval Coleoptera (Lcol) } \\
\hline Adult Coleoptera (Acol) & & & & 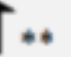 & & & $* * *$ \\
\hline
\end{tabular}

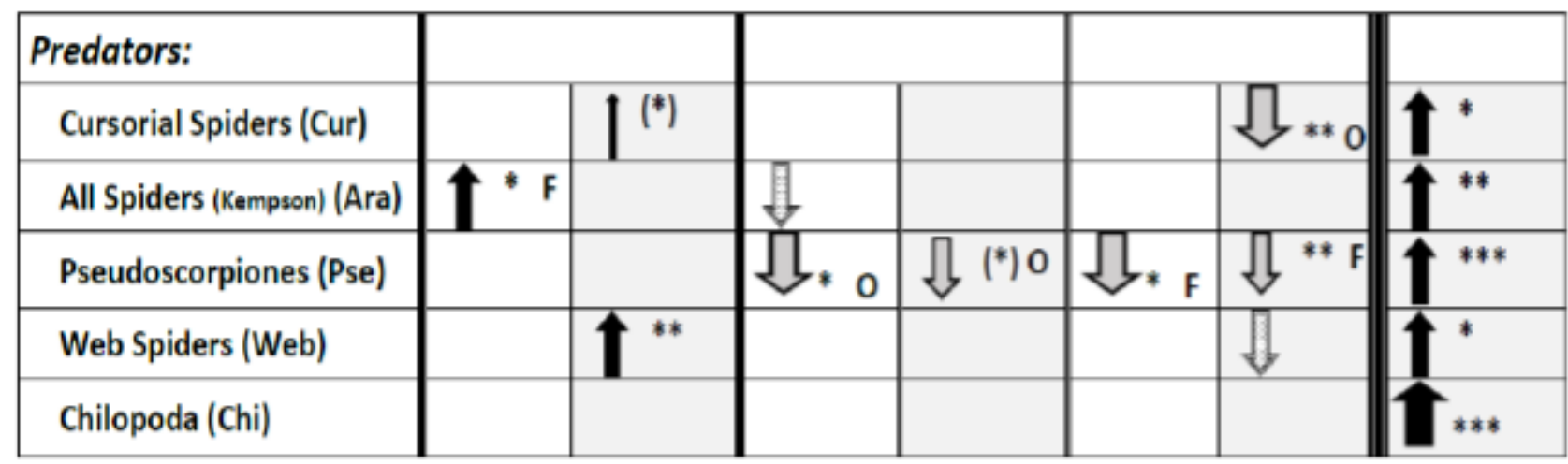

\begin{tabular}{|l|c|c|c|c|c|c|}
\hline $\begin{array}{l}\text { Effect Size } \\
\text { (Suppl. / Control) }\end{array}$ & $\sim 1.5 \mathrm{x}$ & $\sim 2 \mathrm{x}$ & $>3 \mathrm{x}$ & $\sim 0.75 \mathrm{x}$ & $\sim 0.5 \mathrm{x}$ & $\sim 0.3 \mathrm{x}$ \\
\hline Symbol & $\mathbf{1}$ & $\mathbf{1}$ & - & $\mathbb{}$ & $\square$ & $\square$ \\
\hline
\end{tabular}

\begin{tabular}{|l|c|c|}
\hline $\begin{array}{l}\text { Correlation of CAP } \\
\text { Vector with Resource } \\
\text { Addition (Fig. 3) }\end{array}$ & POSITVE & NEGATIVE \\
\hline Symbol & & \\
\hline
\end{tabular}


995 Figure 4. (A) Temporal pattern of responses of all 18 response variables to supplementing

996 the resource base, derived from plots of treatment means over time (Supplementary

997 Appendix S5), statistical modeling of univariate responses (Supplementary Appendix S6),

998 and vector overlays (Fig. 3). Response variables in each category are listed according to

999 descending overall values (Fig. 1). The symbol for the CAP vector only indicates the

1000 direction of the correlation; the width does not reflect the strength of the correlation with

1001 CAP Axis 1. The symbol for the CAP vector only appears if the univariate model failed to

1002 reveal an effect $(P>.10)$. If a vector appears in Fig. 3 for a response variable for which the

1003 univariate statistical modeling revealed an effect, only the arrow summarizing the

1004 univariate model is presented. The width of arrows summarizing effect size for the

1005 univariate model reflects the ratio of Supplemented to Ambient mean values

1006 (Supplementary Appendix S5). The asterisks indicate the $P$ value for the appropriate term

1007 in the univariate statistical model associated with the effect size (Supplementary Appendix

1008 S6) $[(*)=P \leq .10 ; *=P \leq .05 ; * *=P \leq .01 ; * * *=P \leq .001]$. Effects with $P>.10$ are not

1009 indicated, with just one exception (TrpDip, Summer Years 2 and 3; see Table S6.2 in

1010 Supplementary Appendix S6). If there was an interaction with Fencing, the arrow describes

1011 the fencing treatment that displayed a simple Resource effect or a Resource x Year

1012 interaction, indicated by "O" or " $\mathrm{F}$ " to the right of the arrow for Open or Fenced plots,

1013 respectively. Arrows without a letter depict analyses based upon pooled Open and Fenced

1014 plots $(N=10$ / Resource treatment). Arrows and asterisks for Year 1 summarize the simple

1015 Resource effect that year. The pattern for Years 2 and 3 is more complex. An arrow for one

1016 year and a blank cell for the other year indicates a Resource $\mathrm{x}$ Year interaction for that

1017 season. The asterisk refers to the $P$ value of the Resource $\mathrm{x}$ Year interaction. If there is no 
1018 Resource $\mathrm{x}$ Year interaction but there is an overall Resource effect in the model, an arrow is 1019 present for each date and the asterisks reflect the $P$ value of the overall Resource effect. (B)

1020 Results for the study by CW99, which are based upon 3.5 months of adding detritus to open

1021 (unfenced) $2 \times 5$-m plots $(N=10 /$ Resource treatment) (Chen and Wise 1999). N/A = 1022 response variable not sampled. 